\title{
Structural Analysis of Phosphatidylcholines by Post-Source Decay Matrix-Assisted Laser Desorption/Ionization Time-of-Flight Mass Spectrometry
}

\author{
Khalid A. Al-Saad, William F. Siems, and H. H. Hill \\ Department of Chemistry, Washington State University, Pullman, WA, USA \\ Vladimir Zabrouskov \\ Department of Chemistry and Chemical Biology, Baker Lab, 250, Cornell University, Ithaca, NY, USA \\ N. Richard Knowles \\ Department of Horticulture and Landscape Architecture, Washington State University, Pullman, WA, USA
}

\begin{abstract}
The utility of post-source decay (PSD) matrix-assisted laser desorption/ionization time-offlight mass spectrometry (MALDI-TOF-MS) was investigated for the structural analysis of phosphatidylcholine (PC). PC did not produce detectable negative molecular ion from MALDI, but positive ions were observed as both $[\mathrm{PC}+\mathrm{H}]^{+}$and $[\mathrm{PC}+\mathrm{Na}]^{+}$. The PSD spectra of the protonated PC species contained only one fragment corresponding to the head group $(m / z$ 184), while the sodiated precursors produced many fragment ions, including those derived from the loss of fatty acids. The loss of fatty acid from the C-1 position (sn-1) of the glycerol backbone was favored over the loss of fatty acid from the C-2 position (sn-2). Ions emanating from the fragmentation of the head group (phosphocholine) included $[\mathrm{PC}+\mathrm{Na}-$ $59]^{+},[\mathrm{PC}+\mathrm{Na}-183]^{+}$and $[\mathrm{PC}+\mathrm{Na}-205]^{+}$, which corresponded to the loss of trimethylamine (TMA), non-sodiated choline phosphate and sodiated choline phosphate, respectively. Other fragments reflecting the structure of the head group were observed at $m / z 183,146$ and 86 . The difference in the fragmentation patterns for the PSD of $[\mathrm{PC}+\mathrm{Na}]^{+}$compared to $[\mathrm{PC}+\mathrm{H}]^{+}$is attributed to difference in the binding of $\mathrm{Na}^{+}$and $\mathrm{H}^{+}$. While the proton binds to a negatively charged oxygen of the phosphate group, the sodium ion can be associated with several regions of the PC molecule. Hence, in the sodiated PC, intermolecular interaction of the negatively charged oxygen of the phosphate group, along with sodium association at multiple sites, can lead to a complex and characteristic ion fragmentation pattern. The preferential loss of $s n-1$ fatty acid group could be explained by the formation of an energetically favorable six-member ring intermediate, as apposed to the five-member ring intermediate formed prior to the loss of sn-2 fatty acid group. (J Am Soc Mass Spectrom 2003, 14, 373-382) (C) 2003 American Society for Mass Spectrometry
\end{abstract}

$\mathrm{A}$ s major constituents of cell membranes, phospholipids (PL) have an essential role in regulating biophysical properties, protein sorting and cell signaling pathways. Structurally, PLs are diacyl(alkyl)glycerols esterified to a phosphate-containing polar head group. The nature of the head group dictates the particular PL class. PL molecular species are defined by the nature of the acyl (alkyl) residues attached to the C-1 (also called sn-1, using stereospecific numbering) and C-2 positions (sn-2) of the glycerol backbone. The molecular species are uniquely and differentially dis-

Published online March 12, 2003

Address reprint requests to Dr. H. H. Hill, Department of Chemistry, Washington State University, Pullman, WA, USA. E-mail: hhhill@wsu.edu tributed among different tissues [1, 2], and because of their importance in regulating development, function and adaptation [3-5], analysis of PL molecular species and their alterations is of considerable interest in many areas of biological research.

Thin layer chromatography (TLC) [6-8] and normal-phase high performance liquid chromatography (HPLC) $[9,10]$ are well suited for the separation of PL classes, whereas the separation of molecular species within each class may be accomplished using gas chromatography (GC) [11, 12] or reversed-phase HPLC [13-15] (see [5] for a review on lipid molecular species analysis). Conversion of PL species to GCsuitable derivatives is laborious and time consuming, and often results in analyte loss. Moreover, HPLC can 

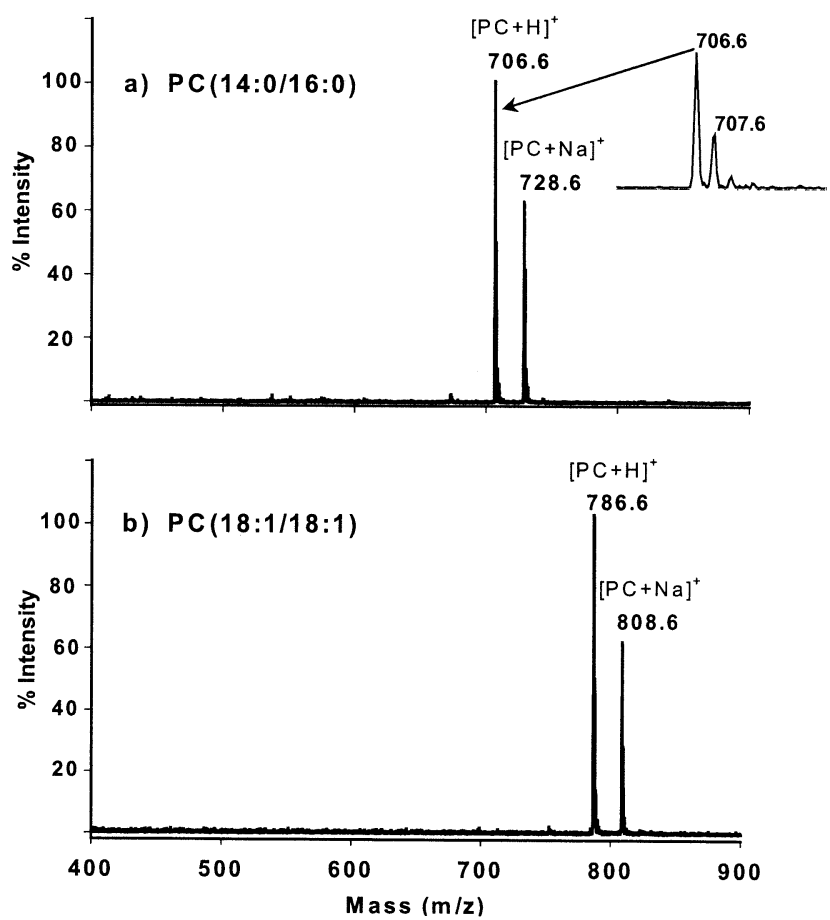

Figure 1. Positive ion MALDI spectra of (a) PC(14:0/16:0) and (b) $\mathrm{PC}(18: 1 / 18: 1)$

lack the required resolving power and sensitivity [5]. Mass spectrometry has also been used for the analysis of PL using several ionization sources, including electron impact [16,17], chemical ionization [18-20], thermospray ionization $[21,22]$ and plasma desorption $[23,24]$. The structural information obtained with these ionization techniques, however, is limited, due to the lack of volatility and the thermal instability of PL $[25,26]$. Softer ionization techniques such as fast atom bombardment (FAB) [26-31] and electrospray ionization (ESI) [32-39] were later proposed for the analysis of intact PL. When coupled with collisionally activated dissociation (CAD), FAB and ESI greatly improved the structural analysis of PL, including identification of fatty acyl moieties and their sn-1/sn-2 positions on the glycerol backbone [40]. Reference [41] provides an overview on mass spectra of phospholipids.

Recently, matrix-assisted laser desorption/ionization (MALDI) interfaced with FTICR [42] and time-offlight [43-50] was introduced as an alternative soft ionization technique for mass analysis of PL. In comparison with the other soft ionization sources (FAB and ESI), MALDI analysis of lipids is more sensitive, less affected by impurities and offers rapid sample preparation, making it an excellent analytical approach for rapid screening of lipid components in biological matrices. While the absence of fragmentation can be beneficial for monitoring the dynamics of previously identified PL molecular species, structural information, particularly that concerning the identity of fatty acid substituents and their positions on the glycerol backbone, has not been obtained using single-stage MALDITOF-MS analysis.

Phosphatidylcholine (PC) (1,2-diacyl-sn-glycero-3phosphocholine) is one of the most predominant membrane phospholipids. In contrast to other PL classes, PC cannot be detected in the negative ion mode as deprotonated molecule, and its positive reflector MALDI spectrum lacks the prompt fragment corresponding to PC minus the polar head group [50]. This is attributed to the unique structure of PC, which contains a positive quaternary nitrogen atom.

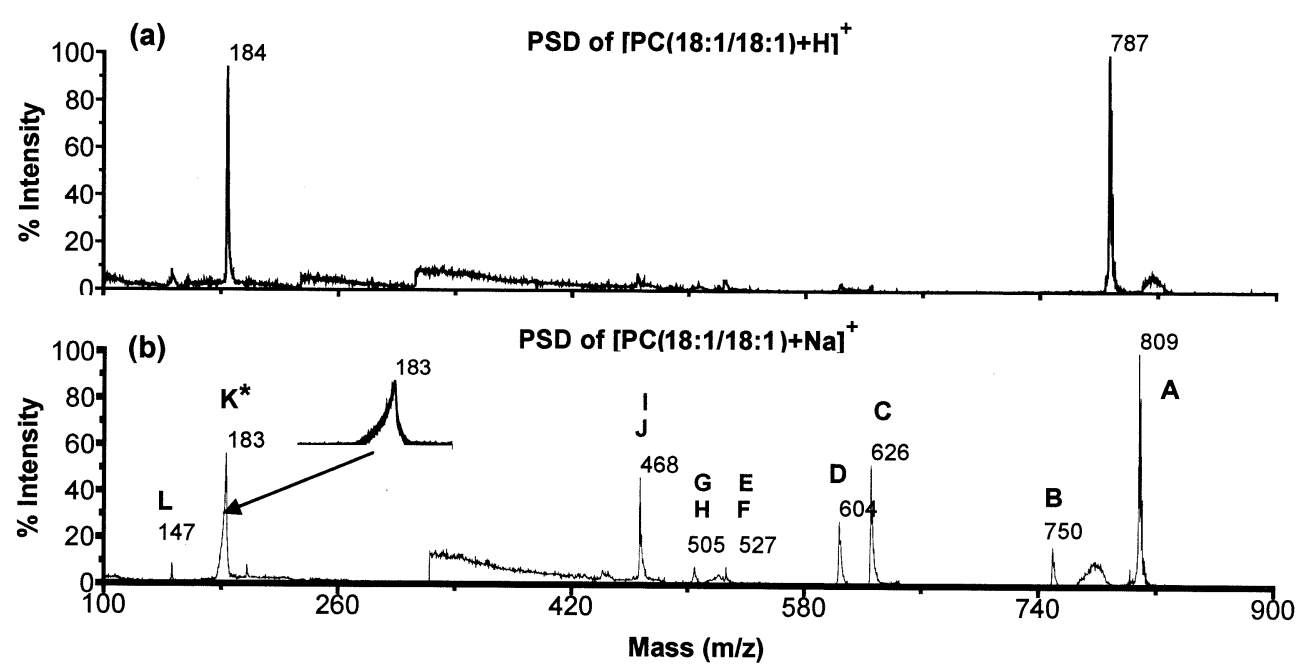

Figure 2. PSD-MALDI spectra of (a) $[\mathrm{PC}(18: 1 / 18: 1)+\mathrm{H}]^{+},(\mathbf{b})[\mathrm{PC}(18: 1 / 18: 1)+\mathrm{Na}]^{+}$. The letters, in Fig. $2 \mathrm{~b}$, correspond to the ions proposed in Table 1. Segments (mirror ratios, MR), laser intensities, and fragments observed in each segment are: MR $100 \%, \mathrm{LI}=$ same as that used in the reflector mode (100\%), A and B; MR $80 \%$, LI $114 \%$, C and D; MR 70\% and $60 \%$, LI $150 \%$, E through F, MR $40 \%, 30 \%$ and 20, LI 114\%, K and $\mathbf{L}$. ${ }^{*}$ The calculated $\mathrm{m} / \mathrm{z}$ for fragment $\mathbf{K}$ (see Table 1 ) is 182 , while experimentally it was observed at 183 . 
Table 1. Proposed structures of fragments observed in the PSD spectra of $[\mathrm{PC}+\mathrm{Na}]^{+}$. Only fragments $\mathrm{K}, \mathrm{L}$ and $\mathrm{M}$ (observed at $m / z 183,147$ and 86, respectively) are independent of the type of PC molecular species.

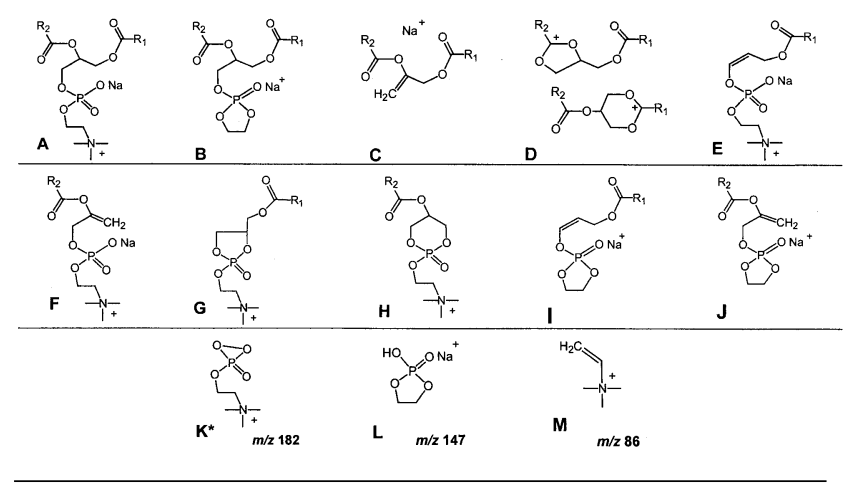

The ionization patterns of $\mathrm{PC}$, relative to other PL classes, have been discussed previously [50]. In this work, we examine the utility of post-source decay (PSD) coupled with MALDI-TOF for the structural identification of PC and propose pathways for the formation of the fragments in the PSD spectra.

In the PSD method, unimolecular decays of laseractivated precursor ions are analyzed. Post-source fragments are formed on a longer time scale than in-source (prompt) fragments. While prompt fragments are formed prior to acceleration, post-source decays occur after acceleration, but before ions enter the electric field of the reflectron. The precursor (parent) ion along with its PSD fragments (which reach the reflectron with the same velocity) are isolated using a timed ion selector. In the reflectron region, ions are separated and focused in several segments by adjusting the mirror ratio of the reflectron. For more details on post-source decay method, see ref [51, 52].

\section{Experimental}

\section{Materials and Sample Preparation}

Solvents were reagent grade and purchased from J. T. Baker (Phillipsburgh, NJ, USA). 2,5-dihydroxybenzoic acid (DHB) was purchased from Aldrich Chemical (Milwaukee, WI, USA). Investigated PC species were obtained from Avanti Polar Lipids Inc. (Alabaster, $\mathrm{AL}$, USA). DHB (0.5 M) in methanol:chloroform $(1: 1, \mathrm{v} / \mathrm{v})$ was used as a matrix solution. PC $(0.04 \mathrm{mg} / \mathrm{mL})$ in chloroform was added to the matrix solution $(1: 1, \mathrm{v} / \mathrm{v})$ and $1 \mu \mathrm{L}$ of the mixture (containing $20 \mathrm{ng}$ of PC) was spotted on a MALDI gold-coated plate. The samples were air-dried for one minute before MALDI analysis.

\section{Instrumentation}

MALDI spectra were obtained using a PerSpective Biosystems (Framingham, MA, USA) Voyager DE-RP time-of-flight mass spectrometer equipped with a nitrogen laser $(337 \mathrm{~nm})$. All spectra were averages of 256 individual laser shots. The laser was adjusted to about $1 / 3$ of its maximum power, depositing approximately $100 \mu \mathrm{J}$ per laser pulse. The potential applied to the target was 25,000 Volts and the focusing guide wire was held at a potential of $0.16 \%$ ( 40 Volts) of the accelerating voltage. A delay time of $140 \mathrm{~ns}$ between the laser pulse and the initiation of the accelerating voltage enabled optimal resolution. For all investigated PCs, MALDI spectra were first acquired in the positive reflector mode from $\mathrm{m} / \mathrm{z} 0$ to 5000 . Spectra were externally calibrated using standard $\mathrm{PC}(16: 0 / 18: 2)$ and $\mathrm{PC}(18: 2 /$ 18:2) (the positive MALDI-TOF spectrum of PC contains peaks corresponding to $[\mathrm{PC}+\mathrm{H}]^{+}$and $[\mathrm{PC}+\mathrm{Na}]^{+}$) $[44,45,49,50]$.

In the PSD experiment, the precursor ions (sodiated and protonated PC species) were isolated using a timed ion selector. The fragment ions were refocused onto the final detector by stepping the voltage applied to the

Table 2. $\mathrm{m} / \mathrm{z}$ values for the fragment ions observed in the PSD spectra of sodiated phosphatidylcholines $\left([\mathrm{PC}+\mathrm{Na}]^{+}\right)$. Fragments $\mathrm{K}, \mathrm{L}$ and $\mathrm{M}$ were always observed at $m / z 183,147$ and 86, respectively, regardless of the type of PC species

\begin{tabular}{|c|c|c|c|c|c|c|c|c|c|c|c|c|c|}
\hline \multirow[b]{2}{*}{$\mathrm{PC}+\mathrm{Na}^{+}$} & \multicolumn{13}{|c|}{ Fragment ions in the PSD-MALDI spectrum of $[\mathrm{PC}+\mathrm{Na}]^{+}$} \\
\hline & A & B & C & D & E & $\mathbf{F}$ & G & $\mathbf{H}$ & $\mathbf{I}$ & $\mathbf{J}$ & $\mathbf{K}^{*}$ & $\mathbf{L}$ & M \\
\hline$(16: 0 / 22: 6)$ & 829 & 770 & 646 & 624 & 501 & 573 & 479 & 551 & 442 & 514 & 183 & 147 & 86 \\
\hline$(18: 0 / 18: 1)$ & 811 & 752 & 628 & 606 & 529 & 527 & 507 & 505 & 470 & 468 & 183 & 147 & 86 \\
\hline$(18: 1 / 18: 0)$ & 811 & 752 & 628 & 606 & 527 & 529 & 505 & 507 & 468 & 470 & 183 & 147 & 86 \\
\hline$(18: 0 / 18: 2)$ & 809 & 750 & 626 & 604 & 529 & 525 & 507 & 503 & 470 & 466 & 183 & 147 & 86 \\
\hline (18:1/18:1) & 809 & 750 & 626 & 604 & 527 & 527 & 505 & 505 & 468 & 468 & 183 & 147 & 86 \\
\hline$(18: 0 / 16: 0)$ & 785 & 726 & 602 & 580 & 529 & 501 & 507 & 479 & 470 & 442 & 183 & 147 & 86 \\
\hline$(16: 0 / 18: 0)$ & 785 & 726 & 602 & 580 & 501 & 529 & 479 & 507 & 442 & 470 & 183 & 147 & 86 \\
\hline$(17: 0 / 17: 0)$ & 785 & 726 & 602 & 580 & 515 & 515 & 493 & 493 & 456 & 456 & 183 & 147 & 86 \\
\hline$(16: 0 / 14: 0)$ & 729 & 670 & 546 & 524 & 501 & 473 & 479 & 451 & 442 & 414 & 183 & 147 & 86 \\
\hline$(14: 0 / 16: 0)$ & 729 & 670 & 546 & 524 & 473 & 501 & 451 & 479 & 414 & 442 & 183 & 147 & 86 \\
\hline$(15: 0 / 15: 0)$ & 729 & 670 & 546 & 524 & 487 & 487 & 465 & 465 & 428 & 428 & 183 & 147 & 86 \\
\hline
\end{tabular}

*The calculated $m / z$ for Fragment $\mathbf{K}$ is 182 (see Table 1), while experimentally it was observed at 182.8 (rounded to 183). 

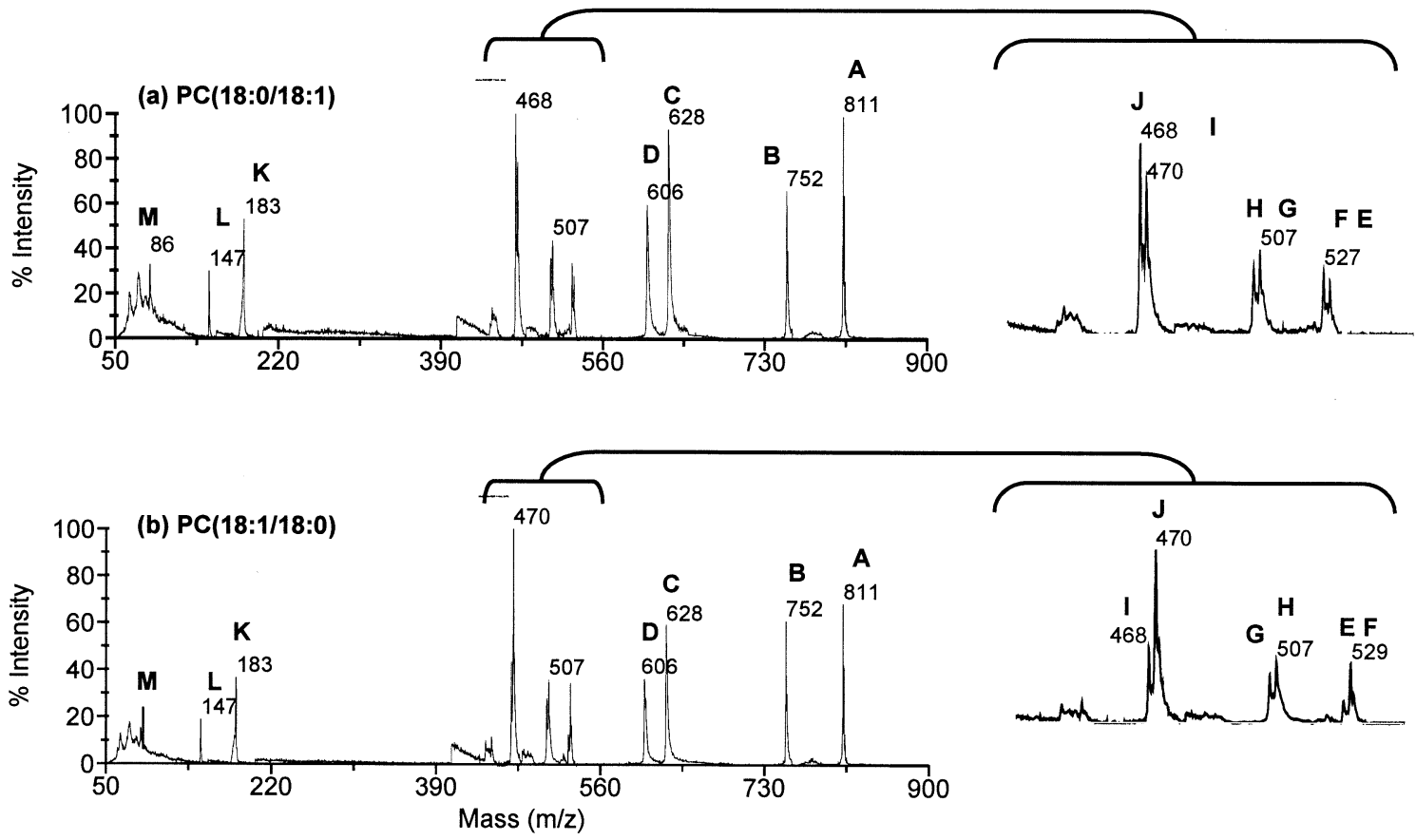

Figure 3. PSD-MALDI spectra of (a) $[\mathrm{PC}(18: 0 / 18: 1)+\mathrm{Na}]^{+}$, (b) $[\mathrm{PC}(18: 1 / 18: 0)+\mathrm{Na}]^{+}$. Segments (mirror ratios, MR), laser intensities, and fragments observed in each segment are: MR 100\%, LI 100\%, A; MR 94\%, LI 107\%, B; MR 80\%, LI 114\%, C and D; MR 66\% and 59\%, LI 150\%, E through F; MR 50\%, $25 \% 19 \%, 15 \%$, LI $114 \%$. Note that the peaks corresponding to the fragments from which $\mathrm{R}_{1} \mathrm{COOH}$ was lost were higher than those from which $\mathrm{R}_{2} \mathrm{COOH}$ was lost (Fragments $\mathbf{J}$ was higher than $\mathbf{I}$, and $\mathbf{F}$ was higher than $E$ ). There was no indication of preferential loss between $R_{1} C O O N a$ and $R_{2} C O O N a$ (see Table 3). The slightly higher intensity of the peak at $m / z 507$ compared to that at $m / z 505$ is due to a partial overlap of their isotopic envelopes.

reflectron in appropriate increments. The individual segments obtained for each mirror ratio were stitched together using the manufacturer's software. The laser intensity was adjusted for each segment to maximize the number of structural fragments. Appropriate mirror ratios (MR) and laser intensities (LI) used in each segment are indicated in the figure captions of all PSD spectra.

\section{Results and Discussion}

\section{MALDI Spectra}

The positive ion MALDI spectra of PC(14:0/16:0) (Figure $1 \mathrm{a})$ and $\mathrm{PC}(18: 1 / 18: 1)$ (Figure $1 \mathrm{~b})$ contained two precursor ions, $[\mathrm{PC}+\mathrm{H}]^{+}$and $[\mathrm{PC}+\mathrm{Na}]^{+}$. Similar MALDI spectra were observed for all PC species, in agreement with previous works [44, 45, 49, 50]. The resolution in the reflector mode was sufficient to obtain isotopic patterns of all analyte peaks.

The ions, $[\mathrm{PC}+\mathrm{H}]^{+}$and $[\mathrm{PC}+\mathrm{Na}]^{+}$, were further analyzed by PSD. The protonated PC precursors produced one fragment corresponding to the head group $(\mathrm{m} / \mathrm{z}$ 184), while the sodiated PC precursors yielded multiple fragment ions, including those reflecting the loss of fatty acid substituents. Figures $2 \mathrm{a}$ and $2 \mathrm{~b}$ show the PSD fragmentation spectra of $[\mathrm{PC}(18: 1 / 18: 1)+\mathrm{H}]^{+}$ and $\left[\mathrm{PC}(18: 1 / 18: 1)+\mathrm{Na}^{+}\right.$, respectively. Capitalized alphabetical letters label the peaks in Figure $2 \mathrm{~b}$ and all the other PSD spectra of sodiated PC species. The letters correspond to the ions proposed in Table 1 . The $\mathrm{m} / \mathrm{z}$ values of the fragment ions observed in the PSD spectra of the sodiated PC species are shown in Table 2.

To examine the utility of PSD for positional analysis of acyl moieties, several isomeric pairs of $\mathrm{PC}$ were studied. PSD spectra of the precursor ions, [PC(18:0/18: $1)+\mathrm{Na}]^{+}$and $[\mathrm{PC}(18: 1 / 18: 0)+\mathrm{Na}]^{+}$, are shown in Figures $3 \mathrm{a}$ and $3 \mathrm{~b}$, respectively. Ions equivalent to $[\mathrm{M}+\mathrm{Na}-$ $59]^{+},[\mathrm{M}+\mathrm{Na}-183]^{+}$and $[\mathrm{M}+\mathrm{Na}-205]^{+}$corresponded, respectively, to the loss of trimethylamine (TMA), choline phosphate and sodiated choline phosphate (labeled B $(m / z ~ 752), \mathbf{C}(m / z 628)$ and $\mathbf{D}(m / z 606)$ in Figure 3). Other ions reflecting fragmentations of the polar head group (K, L and $\mathbf{M}$, Figure 3) had common $\mathrm{m} / \mathrm{z}$ values $(183,147$ and $86 \mathrm{Da})$ in the PSD spectra of all sodiated PC species. The proposed structures of these ions are indicated in Table 1. The three pairs of fragments (EF, $\mathbf{G H}$, and $\mathbf{I J})$ were due to the loss of $\left(\mathrm{R}_{\mathrm{n}} \mathrm{COOH}\right)$, $\left(\mathrm{R}_{\mathrm{n}}\right.$ $\mathrm{COONa})$ and $\left(\mathrm{R}_{n} \mathrm{COOH}+\mathrm{TMA}\right)$, respectively, where $n$ denotes the carbon position ( 1 or 2 ) on the glycerol backbone from which the fatty acid groups were lost.

Figures $4 \mathrm{a}-4 \mathrm{f}$ are PSD spectra of several PC isomeric pairs showing the regions in which $\mathbf{E}$ through $\mathbf{J}$ frag- 

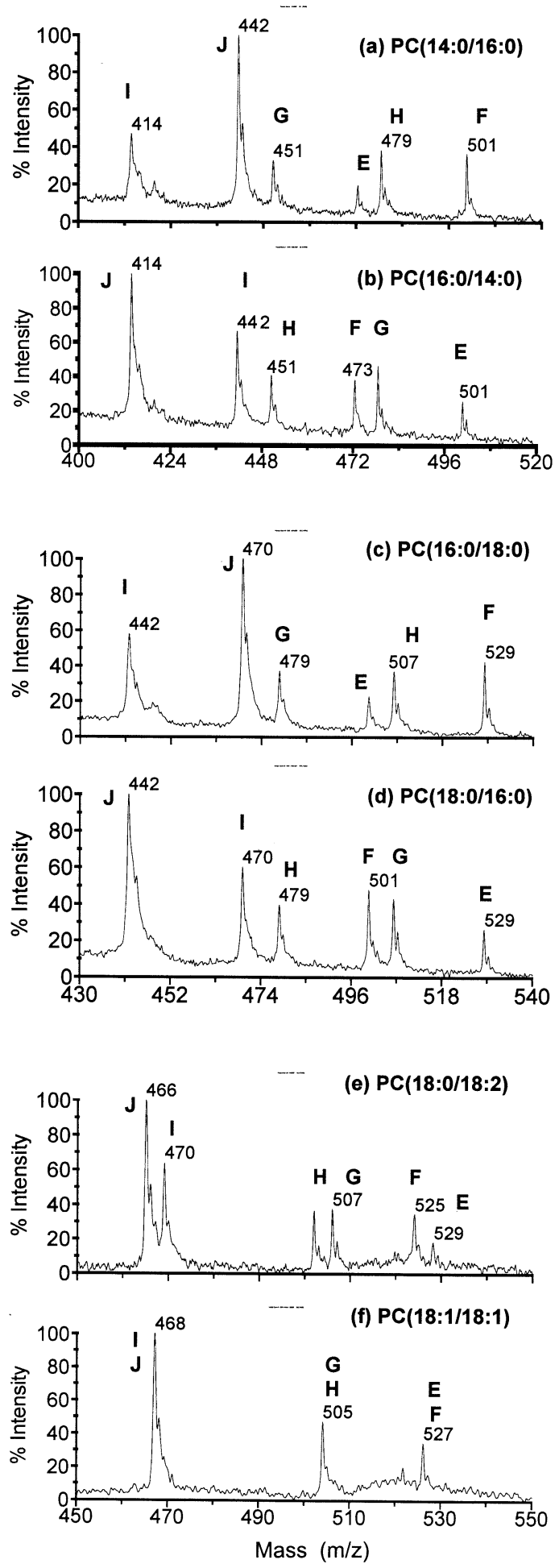

Figure 4. PSD-MALDI spectra of the sodiated precursor ions of several isomeric PC molecular species. (a) $[\mathrm{PC}(14: 0 / 16: 0)+\mathrm{Na}]^{+}$, (b) $[\mathrm{PC}(16: 0 / 14: 0)+\mathrm{Na}]^{+}$, (c) $[\mathrm{PC}(16: 0 / 18: 0)+\mathrm{Na}]^{+}$, (d) $[\mathrm{PC}(18: 0 /$ 16:0)+Na ${ }^{+}$, (e) $[\mathrm{PC}(18: 0 / 18: 2)+\mathrm{Na}]^{+}$, (f) $[\mathrm{PC}(18: 1 / 18: 1)+\mathrm{Na}]^{+}$. The segments in which Fragments $\mathbf{E}$ through $\mathbf{J}$ were observed required mirror ratio of $60 \%$ and laser intensity of $50 \%$ above that used in the reflector mode $(150 \%)$.

ments were observed. To compare relative intensities, the six fragment ions ( $\mathbf{E}$ through $\mathbf{J}$ ) were focused in a
Table 3. Intensity ratios of fragment ions derived from the loss of fatty acyl substituents. The $\mathbf{J}$-fragment: I-fragment ratio and F-fragment: E-fragment ratio were approximately 2:1

\begin{tabular}{|c|c|c|c|}
\hline \multirow[b]{2}{*}{$\mathrm{PC}+\mathrm{Na}^{+}$} & \multicolumn{3}{|c|}{ Fragment ion ratios } \\
\hline & F/E & H/G & $\mathrm{J} / \mathrm{I}$ \\
\hline$(14: 0 / 16: 0)$ & $2.03 \pm 0.15$ & $1.04 \pm 0.06$ & $2.02 \pm 0.05$ \\
\hline$(16: 0 / 14: 0)$ & $2.08 \pm 0.22$ & $1.08 \pm 0.08$ & $1.82 \pm 0.11$ \\
\hline$(16: 0 / 18: 0)$ & $1.98 \pm 0.05$ & $1.07 \pm 0.09$ & $2.02 \pm 0.15$ \\
\hline$(18: 0 / 16: 0)$ & $1.99 \pm 0.03$ & $0.90 \pm 0.05$ & $1.84 \pm 0.06$ \\
\hline$(18: 0 / 18: 2)$ & $1.91 \pm 0.31$ & $0.94 \pm 0.09$ & $1.94 \pm 0.09$ \\
\hline$(16: 0 / 22: 6)$ & $1.96 \pm 0.22$ & $1.04 \pm 0.08$ & $2.20 \pm 0.13$ \\
\hline$(18: 0 / 18: 1)^{*}$ & $1.33 \pm 0.09$ & $0.82 \pm 0.10$ & $1.16 \pm 0.03$ \\
\hline$(18: 1 / 18: 0)^{*}$ & $2.69 \pm 0.47$ & $1.21 \pm 0.08$ & $2.40 \pm 0.13$ \\
\hline
\end{tabular}
overlapping of isotopic distribution (see Fig. 3).

single segment. It is clear from the spectra that loss of the $s n-1$ fatty acid group from the glycerol backbone was favored over the loss of $s n-2$ fatty acid group. The intensity of fragment $\mathbf{F}$ (formed from the loss of $\mathrm{R}_{1} \mathrm{COOH}$ ) was always higher than that of fragment $\mathbf{E}$ (formed from the loss of $\mathrm{R}_{2} \mathrm{COOH}$ ). Also, the intensity of fragment $\mathbf{J}$ (formed from the loss of both $\mathrm{R}_{1} \mathrm{COOH}$ and TMA) was always higher than that of fragment I (formed from the loss of both $\mathrm{R}_{2} \mathrm{COOH}$ and TMA). The J-fragment: I-fragment ratio was approximately 2:1 in all PC species, (see Table 3). Other PL classes (PE, PG, PA and PS) have shown (qualitatively) the same preferential loss of fatty acids [48]. For PC species with identical fatty acyl groups (e.g., PC(18:1/18:1), Figure $4 \mathrm{f})$, the fragments in each pair $(\mathbf{E F}, \mathbf{G H}$, and $\mathbf{I J})$ had the same $m / z$, resulting in three signals reflecting the losses of $\left(\mathrm{R}_{n} \mathrm{COOH}\right),\left(\mathrm{R}_{n} \mathrm{COONa}\right)$ and $\left(\mathrm{R}_{\mathrm{n}} \mathrm{COOH}+\mathrm{TMA}\right)$.

\section{Fragmentation Mechanisms}

Unlike the protonated PC species, several fragment ions were observed in PSD spectra of the sodiated PC species, concordant with previous work by Domingues et al. [26] (FAB-tandem-MS), and Han et al. [34] (ESI-tandem-MS). The nature of ionic binding of alkali metal, as opposed to proton binding [53] may be responsible for the multiple fragments observed in the PSD spectra of sodiated PC. While the proton gets exclusively bound to a negatively charged phosphate oxygen, sodium ion can randomly associate with several regions of the PC molecule. As a result, the negatively charged oxygen in the sodiated PC may exhibit intermolecular nucleophilic attacks, leading to the loss of $\mathrm{R}_{\mathrm{n}} \mathrm{COOH}$ and TMA from sodiated PC. In protonated PC, however, the proton bound to the phosphate oxygen precludes such intermolecular interactions. 
<smiles>[R]C(=O)OCC(COP(=O)([O-])OC[N+](C)(C)C)OC([R])=O</smiles>

a) neutral PC<smiles>[R]C(=O)OCC(COP(=O)(O)OC[N+](C)(C)C)OC([R])=O</smiles>

b) $\mathrm{PC}+\mathrm{H}^{+}$

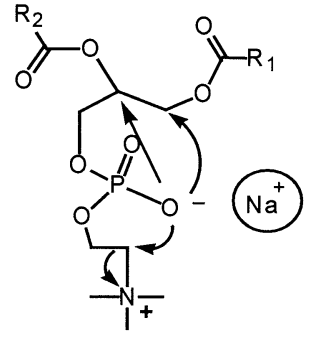

c) $\mathrm{PC}+\mathrm{Na}^{+}$

Scheme 1

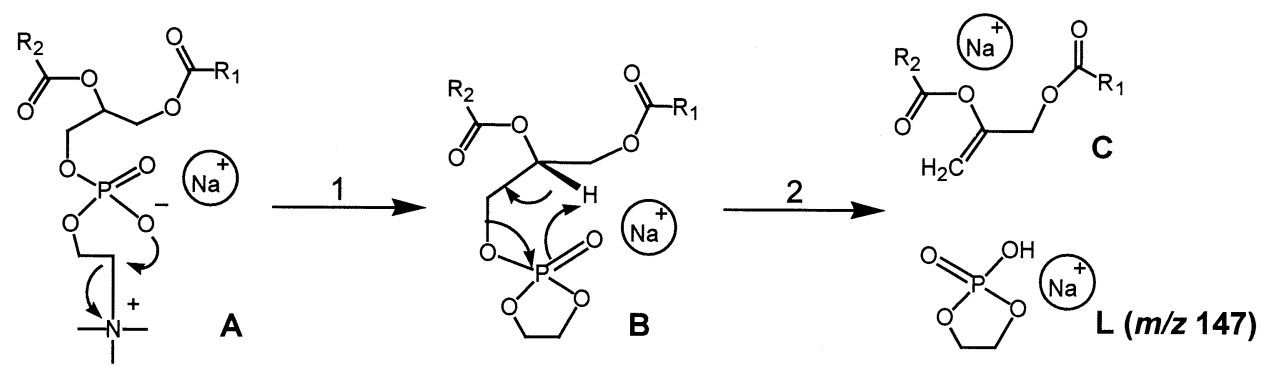

Scheme 2

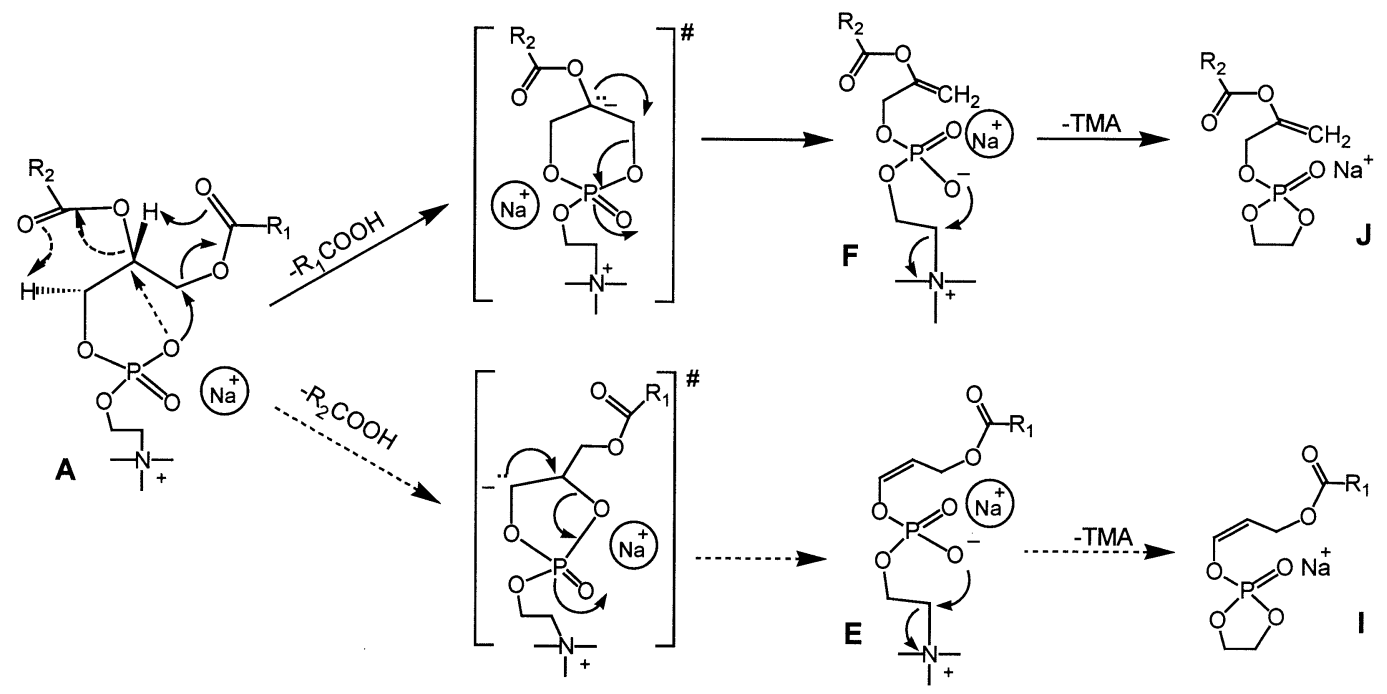

Scheme 3

The proton and sodium binding to the PC molecule and possible intermolecular interaction exhibited in the sodiated PC are illustrated in Scheme 1, where the encircled sodium ion indicates that the sodium position is irrelevant with regard to initiating the fragmentation that results in the loss of $\mathrm{R}_{n} \mathrm{COOH}$ and TMA. The losses of $\mathrm{R}_{n} \mathrm{COONa}$ and sodiated choline phosphate, on the other hand, are fragmentations in which the position of the sodium ion is relevant. In other words, the availability of sodium ion to associate with fatty acyl or polar head groups may effect their neutral losses as sodium salts $\left(R_{n}\right.$ COONa and sodiated choline phosphate).
Pathways for several fragments observed in the PSD spectra of sodiated PC may be explained by the labile nature of the sodium attachment and the intermolecular interaction of the negative phosphate group. As illustrated in Scheme 2, intermolecular nucleophilic attack by the negatively charged oxygen of the phosphate group evidently led to the loss of TMA (Scheme 2, Pathway 1), yielding Fragment B. In Fragment B, a six-membered-ring cyclic rearrangement could have occurred (Scheme 2, Pathway 2). Since the sodium ion may be associated with either the polar head or the fatty acid group, the cyclic rearrangement led to the fragment ions C and $\mathbf{L}$. The lack of an ion at $\mathrm{m} / \mathrm{z} 206$ 


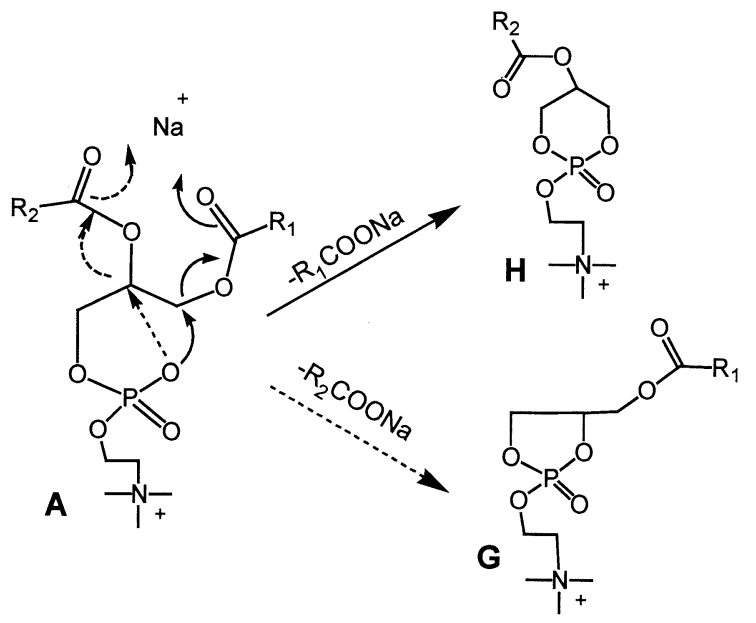

Scheme 4

(corresponding to the sodiated polar head) suggests that the cyclic rearrangement (Pathway 2) occurred after the loss of TMA (Pathway 1).

Loss of $\mathrm{R}_{1} \mathrm{COOH}$ from the sodiated PCs was favored over the loss of $\mathrm{R}_{2} \mathrm{COOH}$. This preferential loss was also observed with ESI-tandem MS of lithiated PC, by Hsu et al. [37]. Unlike the lithiated PC species, the ESI-tandem mass spectra of protonated PC species contained no abundant ions that identified the fatty acid groups [37]. The pathway proposed by Hsu et al. [37] suggested that $\mathrm{R}_{\mathrm{n}} \mathrm{COOH}$ were lost via charge-remote six membered cyclic rearrangements in which the carbonyl oxygens of the fatty acids gained a proton from the glycerol backbone, leading to the neutral loss of fatty acid groups.

Here we propose alternative pathways (Scheme 3 ) that explain the different fragmentation patterns obtained for the sodiated and protonated PC species. In addition, Scheme 3 provides a rational for the preferential loss of fatty acid from the $s n-1$ position. It is likely that in a sodiated PC, a negatively charged phosphate oxygen exhibits intermolecular nucleophilic attacks on the carbons of the glycerol backbone, forming cyclic intermediate ions (Scheme 3). We suggest that the formation of PC minus $\mathrm{R}_{\mathrm{n}} \mathrm{COOH}(\mathbf{F}$ and $\mathbf{E})$ and subsequently PC minus both $\mathrm{R}_{\mathrm{n}} \mathrm{COOH}$ and TMA (I and $\mathbf{J}$ ) are determined by differences in the activation energies needed for the formation of the energetic cyclic intermediates (in brackets, Scheme 3). The energetically

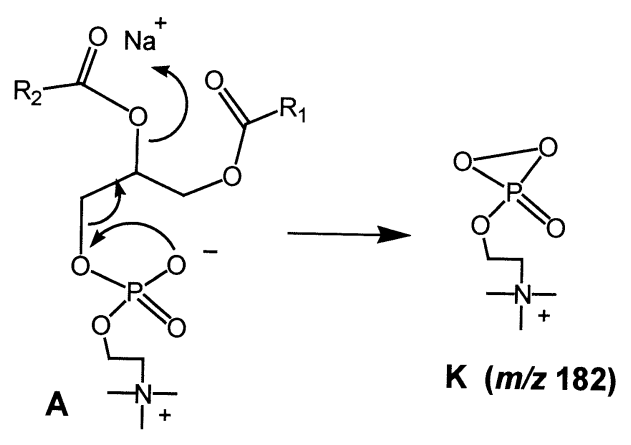

Scheme 6

more favorable formation of the six-member intermediate compared to that of the five-member intermediate could account for the preferential loss of the $s n-1$ fatty acid substituent.

Proposed pathways leading to the loss of fatty acids as neutral sodium salts $\left(\mathrm{R}_{n} \mathrm{COONa}\right)$ are illustrated in Scheme 4. Interestingly, while sodiated PC species were susceptible to the simultaneous loss of $\mathrm{R}_{\mathrm{n}} \mathrm{COOH}$ and TMA (Fragments $\mathbf{I}$ and $\mathbf{J}$, Scheme 3 ), ions that lost $\mathrm{R}_{\mathrm{n}} \mathrm{COONa}$ did not lose TMA and vice-versa. This supports the proposed involvement of the negatively charged phosphate oxygen in the fragmentation pathways. The cyclic structures formed via the loss of $\mathrm{R}_{\mathrm{n}} \mathrm{COONa}$ (Fragments $\mathbf{H}$ and $\mathbf{G}$, Scheme 4) no longer contained negatively charged oxygen and thus did not lose TMA. Likewise, when sodiated PC lost TMA, a cyclophosphane ring was formed (Fragment B, Scheme 2), precluding the loss of $\mathrm{R}_{\mathrm{n}} \mathrm{COONa}$.

There was no indication of a preferential loss between $\mathrm{R}_{1} \mathrm{COONa}$ and $\mathrm{R}_{2} \mathrm{COONa}$ (Fragment $\mathbf{G} \cong \mathbf{H}$, see Table 3). This suggests that, unlike the loss of $\mathrm{R}_{n} \mathrm{COOH}$ groups, which is dictated by the activation energy for the formation of cyclic intermediates, the loss of $\mathrm{R}_{\mathrm{n}} \mathrm{COONa}$ is likely determined by the probability of sodium ion to interact with carbonyl groups of the fatty acyl chains. Thus, since it is equally likely for a sodium ion to associate with either carbonyl group ( $s n-1$ or $s n-2)$, the loss of $\mathrm{R}_{1} \mathrm{COONa}$ was as frequent as the loss of $\mathrm{R}_{2} \mathrm{COONa}$. Similarly, the association of sodium ion with the head group (the choline phosphate), led to an ion formed by the neutral loss of sodiated choline

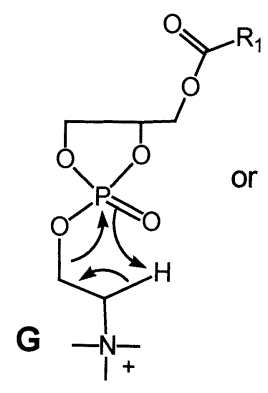

Scheme 5

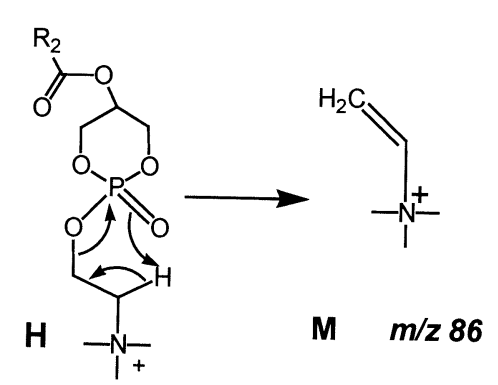

Scheme 7 


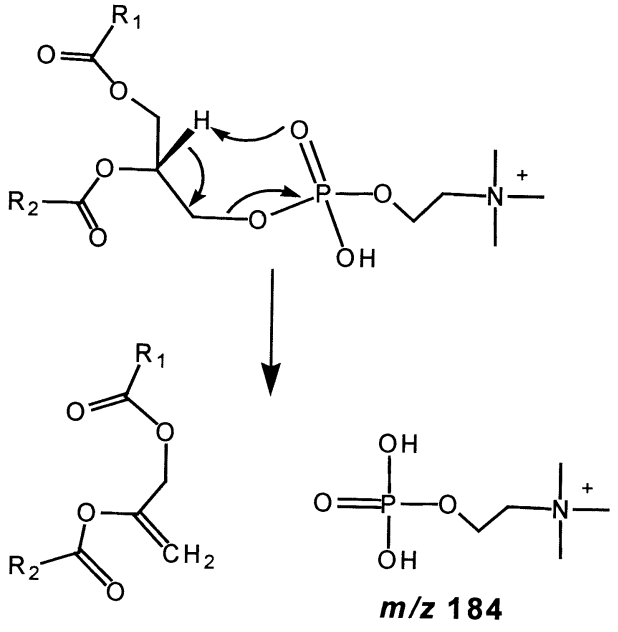

Scheme 8

phosphate from sodiated PC (Fragment D), as illustrated in Scheme 5.

Possible mechanisms leading to Fragments $\mathbf{K}$ and $\mathbf{M}$ are illustrated in Schemes $\mathbf{6}$ and 7, respectively. The calculated $\mathrm{m} / \mathrm{z}$ of Fragment $\mathbf{K}$ is 182 , while experimentally it was observed at 182.8 (rounded to 183). The higher observed $m / z$ value for Fragment K may be due to the contribution of a fragment generated from the protonated PC at $\mathrm{m} / \mathrm{z} 184$ (the protonated PC cannot be completely eliminated when selecting the sodiated PC). This also explains the broad asymmetric appearance of the peak corresponding to Fragment K (see Figure 2b), despite attempts to optimize it by adjusting the mirror ratio of the reflector. The Fragment $\mathbf{M}$ at $\mathrm{m} / \mathrm{z} 86$ was observed among other poorly resolved peaks between $\mathrm{m} / \mathrm{z} 50$ and 100 (Figure 3). These peaks likely correspond to the same series of broad peaks that have been observed in FAB-CID spectra of $[\mathrm{PC}+\mathrm{Na}-205]^{+}$[26]. According to Domingues et al. [26], the peaks may be attributed to ions derived from charge-remote fragmentation of the alkyl chains.

Finally, the fragment at $m / z 184$ in the PSD spectra of protonated PC species may arise upon transfer of a proton from the glycerol backbone to the phosphate group, via a six-membered cyclic rearrangement, as illustrated in Scheme 8. The cleavage resulting from this proton transfer leaves a net positive charge on the head group of the fragment, observed at $\mathrm{m} / \mathrm{z} 184$. As previously mentioned, a fragment ion at $\mathrm{m} / \mathrm{z} 206$ was not observed in the PSD spectra of sodiated PC species. This is likely because a negative charge of the phosphate group precludes the cyclic rearrangement of sodiated PC and in-turn precludes the C-O cleavage, as illustrated in Scheme 9.

\section{Conclusions}

PSD-MALDI spectra of sodiated PC species are more informative than PSD spectra of protonated PC spe-

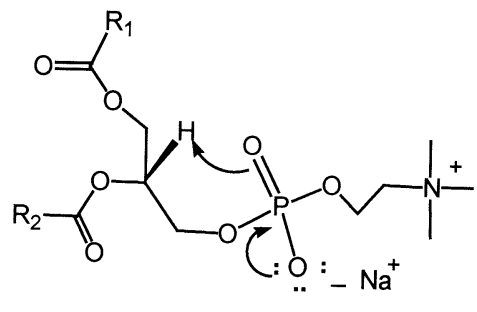

Scheme 9

cies. The labile ionic association of sodium ion with the PC molecule is likely the promoter of several fragmentation pathways. On the other hand, the binding of a proton to the phosphate group primarily leads to the formation of an ion at $m / z 184$, corresponding to the head group itself. The preferential loss of $s n-1$ fatty acid group from sodiated PC is likely due to the lower activation energy needed to form the six-membered ring intermediate ion, as opposed to the five-membered ring formed prior to the loss of $s n-2$ fatty acid group. This phenomenon makes it possible to identify the fatty acyl groups and their positions on the glycerol backbone of a PC molecule via PSD-MALDI MS.

\section{References}

1. Gross, R. W. Identification of Plasmalogen as the Major Phospholipid Constituent of Cardiac Sarcoplasmic Reticulum. Biochemistry 1985, 24, 1662-1668.

2. Ohlrogge, J.; Browse, J. Lipids Biosynthesis. The Plant Cell $1995,7,957-970$.

3. Lynch, D. V.; Thompson, G. A., Jr. Microsomal Phospholipid Molecular Species Alterations During Low Temperature Acclimation in Dunaliella [Salina, Algae, Changes in the Microsomal Membrane Acyl Chain Composition of the Polar Lipid]. Plant Physiol. 1984, 74, 193-197.

4. Grieva, S. J.; Littleton, J. M.; Jones, P.; John, G. R., Jr. Functional Tolerance to Ethanol in Mice: Relationship to Lipid Metabolism. Pharm. Pharmacol. 1979, 31, 737-742.

5. Olsson, N. U.; Salem, N., Jr. Molecular Species Analysis of Phospholipids. J. Chromatogr. B 1997, 692, 245-256.

6. Skipski, V. P.; Smolowe, A. F.; Sullivan, R. C.; Barclay, M. Separation of Lipid Classes by Thin-Layer Chromatography. Biochim. Biophys. Acta 1965, 106, 386-396.

7. Freeman, C. P.; West, D. Complete Separation of Lipid Classes on a Single Thin-Layer Plate. J. Lipid Res. 1966, 7, 324-327.

8. Hojnacki, J. L.; Smith, S. C. Separation of Six Lipid Classes on One Thin-Layer Chromatogram. J. Chromatogr. 1974, 90, 364367.

9. Hamilton, J. G.; Comai, K. Separation of Neutral Lipid, Free Fatty Acid and Phospholipid Classes by Normal Phase Hplc. Lipids 1988, 23, 1150-1153.

10. Grizard, G.; Sion, B.; Bauchart, D.; Boucher, D. Separation and Quantification of Cholesterol and Major Phospholipid Classes in Human Semen by High-Performance Liquid Chromatography and Light-Scattering Detection. J. Chromatogr. B Biomed. Sci. Appl. 2000, 740, 101-107.

11. Myher, J. J.; Kuksis, A. Resolution of Diacyl-Glycerol Moieties of Natural Glycerophospholipids by Gas-Liquid Chromatography on Polar Capillary Columns. Can. J. Biochem. 1982, 60, 638-650. 
12. Myher, J. J.; Kuksis, A. General Strategies in Chromatographic Analysis of Lipids. J. Chromatogr. B Biomed Appl. 1995, 671, 3-33.

13. Smith, M.; Jungalwala, F. B. Reversed-Phase High Performance Liquid Chromatography of Phosphatidylcholine: A Simple Method for Determining Relative Hydrophobic Interaction of Various Molecular Species. J. Lipid Res. 1981, 22, 697-704.

14. Sotirhos, N.; Thorngren, C.; Herslof, B. Reversed-Phase HighPerformance Liquid Chromatographic Separation and Mass Detection of Individual Phospholipid Classes. J. Chromatogr. 1985, 331, 313-320.

15. Abidi, S. L.; Mounts, T. L. High-Performance Liquid Chromatographic Separation of Molecular Species of Neutral Phospholipids. J. Chromatogr. 1992, 598, 209-218.

16. Perkins, E. G.; Johnson, P. V. Pyrolysis-Gas Chromatography of Phosphoglycerides: A Mass Spectral Study of the Products. Lipids 1969, 4, 301-303.

17. Klein, R. A. Mass Spectrometry of the Phosphatidyl Amino Alcohols: Detection of Molecular Species and Use of Low Voltage Spectra and Metastable Scanning in the Elucidation of Structure. J. Lipid Res. 1972, 13, 672-679.

18. Crawford, C. G.; Plattner, R. D. Ammonia Chemical Ionization Mass Spectrometry of Intact Diacyl Phosphatidylcholine. J. Lipid Res. 1983, 24, 456-460.

19. Bisseret, P.; Nakatani, Y.; Ourisson, G.; Hueber, R.; Teller, G. Ammonia Chemical Ionization Mass Spectrometry of Lecithins on a Gold Support. Chem. Phys. Lipids 1983, 33, 383-392.

20. Jungalwala, F. B.; Evans, J. E.; McCluer, R. H. Compositional and Molecular Species Analysis of Phospholipids by High Performance Liquid Chromatography Coupled with Chemical Ionization Mass Spectrometry. J. Lipid Res. 1984, 25, 738-749.

21. Kim, H. Y.; Salem, N., Jr. Phospholipids Molecular Species Analysis by Thermospray Liquid Chromatography/Mass Spectrometry. Anal. Chem. 1986, 59, 9-14.

22. Kim, H.-Y.; Salem, J. Norman Application of Thermospray High-Performance Liquid Chromatography/Mass Spectrometry for the Determination of Phospholipids and Related Compounds. Anal. Chem. 1987, 59, 722-726.

23. Cotter, R. J.; Tabet, J. C. Laser Desorption Mass Spectrometry: Mechanisms and Applications. Int. J. Mass Spectrom. 1983, 53, 151-166.

24. Seydel, U.; Lindner, B.; Zahringer, U.; Rietschel, E. T.; Kusumoto, S.; Shiba, T. Laser Desorption Mass Spectrometry of Synthetic Lipid a-Like Compounds. Biomed Mass Spectrom 1984, 11, 132-141.

25. Marai, L.; Myher, J. J.; Kuksis, A. Analysis of Triacylglycerols by Reversed-Phase High Pressure Liquid Chromatography with Direct Liquid Inlet Mass Spectrometry. Can. J. Biochem. Cell Biol. 1983, 61, 840-849.

26. Domingues, P.; Domingues, M. R. M.; Amado, F. M. L.; Ferrer-Correia, A. J. Characterization of Sodiated Glycerol Phosphatidylcholine Phospholipids by Mass Spectrometry. Rapid Commun. Mass Spectrom. 2001, 15, 799-804.

27. Chilton, F. H., III; Murphy, R. C. Fast Atom Bombardment Analysis of Arachidonic Acid-Containing Phosphatidylcholine Molecular Species. Biomed. Environ. Mass Spectrom. 1986, 13, 71-76.

28. Jensen, N. J.; Tomer, K. B.; Gross, M. L. Fast Atom Bombardment and Tandem Mass Spectrometry of Phosphatidylserine and Phosphatidylcholine. Lipids 1986, 21, 580-588.

29. Huang, Z. H.; Gage, D. A.; Sweeley, C. C. Characterization of Diacylglycerophosphocholine Molecular Species by Fab-CadMs/Ms: A General Method Not Sensitive to the Nature of Fatty Acyl Groups. J. Am. Soc. Mass Spectrom. 1992, 3, 71-78.

30. Kayganich, K. A.; Murphy, R. C. Fast Atom Bombardment Tandem Mass Spectrometric Identification of Diacyl, Alkyla- cyl, and Alk-1-Enylacyl Molecular Species of Glycerophosphoethanolamine in Human Polymorphonuclear Leukocytes. Anal. Chem. 1992, 64, 2965-2971.

31. Murphy, R. C.; Harrison, K. A. Fast Atom Bombardment Mass Spectrometry of Phospholipids. Mass Spectrom. Rev. 1994, 13, $57-75$.

32. Kerwin, J. L.; Tuininga, A. R.; Ericsson, L. H. Identification of Molecular Species of Glycerophospholipids and Sphingomyelin Using Electrospray Mass Spectrometry. J. Lipid Res. 1994, $35,1102-1114$

33. Han, X.; Gross, R. W. Electrospray Ionization Mass Spectroscopic Analysis of Human Erythrocyte Plasma Membrane Phospholipids. Proc. Natl. Acad. Sci. U.S.A. 1994, 91, 10635 10639.

34. Han, X.; Gross, R. W. Structural Determination of Picomole Amount of Phospholipids Via Electrospray Ionization Tandem Mass Spectrometry. J. Am. Soc. Mass Spectrom. 1995, 6, 1202-1210.

35. Smith, P. B.; Snyder, A. P.; Harden, C. S. Characterization of Becterial Phospholipids by Electrospray Ionization Tandem Mass Spectrometry. Anal. Chem. 1995, 67, 1824-1830.

36. Hvattum, E.; Hagelin, G.; Larsen, Å. Study of Mechanisms Involved in the Collision-Induced Dissociation of Carboxylate Anion from Glycerophospholipids Using Negative Ion Electrospray Tandem Quadrupole Mass Spectrometry. Rapid Commun. Mass Spectrom. 1998, 12, 1405-1409.

37. Hsu, F.-F.; Bohrer, A.; Turk, J. Formation of Lithiated Adducts of Glycerophosphocholine Lipids Facilitates Their Identification by Electrospray Ionization Tandem Mass Spectrometry. J. Am. Soc. Mass Spectrom. 1998, 9, 516-526.

38. Hsu, F.-F.; Turk, J. Charge-Driven Fragmentation Processes in Diacyl Glycerophosphatidic Acids Upon Low-Energy Collisional Activation. A Mechanistic Proposal. J. Am. Soc. Mass Spectrom. 2000, 11, 797-803.

39. Hsu, F.-F.; Turk, J. Characterization of Phosphatidylinositol, Phosphatidylinositol-4-Phosphate, and Phosphatidylinositol4,5-Bisphosphate by Electrospray Ionization Tandem Mass Spectrometry: A Mechanistic Study. J. Am. Soc. Mass Spectrom. 2000, 11, 986-999.

40. Koivusalo, M.; Haimi, P.; Heikinheimo, L.; Kostiainen, R. Quantitative Determination of Phospholipid Compositions by Esi-Ms: Effects of Acyl Chain Length, Unsaturation, and Lipid Concentration on Instrument Response. Journal of Lipid Research 2001, 42, 663-672.

41. Murphy, R. C. Illuminati Press: Denver, 2002.

42. Marto, J. A.; White, F. M.; Seldomridge, S.; Marshall, A. G. Structural Characterization of Phospholipids by Matrix-Assisted Laser Desorption/Ionization Fourier Transform Ion Cyclotron Resonance Mass Spectrometry. Anal. Chem. 1995, 67, 3979-3984.

43. Harvey, D. J. Matrix-Assisted Laser Desorption/Ionization Mass Spectrometry of Phospholipids. J. Mass Spectrom. 1995, 30, 1333-1346.

44. Benard, S.; Arnhold, J.; Lehnert, M.; Schiller, J.; Arnold, K. Experiments Towards Quantification of Saturated and Polyunsaturated Diacylglycerols by Matrix-Assisted Laser Desorption and Ionization Time-of-Flight Mass Spectrometry. Chem. Phys. Lipids 1999, 100, 115-125.

45. Schiller, J.; Arnhold, J.; Benard, S.; Muller, M.; Reichl, S.; Arnold, K. Lipids Analysis by Matrix-Assisted Laser Desorption and Ionization Mass Spectrometry: A Methodological Approach. Anal. Biochem. 1999, 267, 46-56.

46. Petkovic, M.; Schiller, J.; Müller, M.; Benard, S.; Reichl, S.; Arnold, K.; Arnhold, J. Detection of Individual Phospholipids in Lipid Mixtures by Matrix-Assisted Laser Desorption/Ionization Time-of-Flight Mass Spectrometry: Phosphatidylcho- 
line Prevents the Detection of Further Species. Anal. Biochem. 2001, 289, 202-216

47. van den Brink, O. F.; Boon, J. J.; O'Connor, P. B.; Duursma, M. C.; Heeren, R. M. A. Matrix-Assisted Laser Desorption/ Ionization Fourier Transform Mass Spectrometric Analysis of Oxygentated Triglycerides and Phosphatidylcholines in Egg Tempra Paint Dosimeters Used for Environmental Monitoring of Museum Display Conditions. J. Mass Spectrom. 2001, 36, $479-492$.

48. Al-Saad, K. A.; Zabrouskov, V.; Siems, W. F.; Knowles, N. R.; Hannan, R. M.; Hill, H. H., Jr. Structural Determination of Phospholipids Molecular Species by Matrix-Assisted Laser Desorption Ionization Time-of-Flight Mass Spectrometry. Proceeding of the 49th ASMS Conference: Chicago Illinois, May 2001.

49. Zabrouskov, V.; Al-Saad, K. A.; Siems, W. F.; Hill, H. H., Jr.; Knowles, N. R. Analysis of Plant Phosphatidylcholines by Matrix-Assisted Laser Desorption/Ionization Time-of-Flight
Mass Spectrometry. Rapid Commun. Mass Spectrom. 2001, 15, 935-940.

50. Al-Saad, K. A.; Zabrouskov, V.; Siems, W. F.; Knowles, N. R.; Hannan, R. M.; Hill, H. H., Jr. Matrix-Assisted Laser Desorption/Ionization Time-of-Flight Mass Spectrometry of Lipids: Ionization and Prompt Fragmentation Patterns. Rapid Commun. Mass Spectrom. 2003, 17, 87-96.

51. Spengler, B.; Kirsch, D.; Kaufmann, R. Metastable Decay of Peptides and Proteins in Matrix-Assisted Laser-Desorption Mass Spectrometry. Rapid Commun. Mass Spectrom. 1991, 5, 198-202.

52. Kaufmann, R.; Chaurand, P.; Kirsch, D.; Spengler, B. PostSource Decay and Delayed Extraction in Matrix-Assisted Laser Desorption/Ionization-Reflectron Time-of-Flight Mass Spectrometry. Are There Trade-Offs? Rapid Commun. Mass Spectrom. 1996, 10, 1199-1208.

53. Siuzdak, G. Mass Spectrometry for Biotechnology. Academic Press: San Diego, 1996; 18-19. 